\title{
Hairy leukaemic cell influx into the cerebrospinal fluid secondary to encephalomyelitis
}

\author{
A.S. Wierzbicki, R. Luxton'1, B.N. McLean'1, C. Gilois, P.M. Norman and \\ E.J. Thompson ${ }^{1}$
}

Department of Haematology and ${ }^{1}$ Department of Special Chemical Pathology, National Hospitals for Neurology and Neurosurgery, Queen Square, London WC1N 3BG, UK

\begin{abstract}
Summary: A case report of a 53 year old male with hairy cell leukaemia is presented in whom encephalomyelitis caused by toxoplasmosis resulted in an influx of hairy cells into the cerebrospinal fluid following disruption of the blood-brain barrier. These cells subsequently disappeared as the barrier reformed. It is suggested that the presence of hairy cells in the cerebrospinal fluid is a secondary self-limiting phenomenon.
\end{abstract}

\section{Introduction}

Hairy cell leukaemia (HCL) is a B-cell lymphoproliferative disease with a predilection for males and a relatively benign course. It has only mild immunosuppressive effects and patients have a reasonable prognosis following splenectomy and/ or interferon therapy. It has been extensively described as a systemic tumour but reports of central nervous system involvement are rare. We would like to describe a case in which secondary temporary infiltration of the cerebrospinal fluid (CSF) was seen following severe encephalomyelitis.

\section{Case report}

A 53 year old male who had been diagnosed as suffering from hairy cell leukaemia 8 years previously and had been treated by splenectomy 7 years ago presented with confusion, malaise, agitation and pyrexia $\left(37.8^{\circ} \mathrm{C}\right)$. His previous history included two episodes of pneumonia (including one Legionella pneumophila infection) in the last 2 years and he had recently returned from southern Portugal and the Black Forest (Germany). There were no clinical signs apart from impaired orientation, mild dysphasia and a positive Kernig's sign. A provisional diagnosis of encephalomyelitis was made.

Correspondence: A.S. Wierzbicki, M.A., D.Phil., B.M., B.Ch., Department of Medical Biochemistry, University Hospital of Wales, Heath Park, Cardiff CF4 4XW, UK. Accepted: 29 January 1993
The patient was treated with intravenous acyclovir and antimicrobials including ampicillin, gentamicin and later sulphamethoxazole/trimethoprim. He made a slow but uneventful recovery and continues to be well.

\section{Investigations}

CSF was obtained by lumbar puncture and cytospin preparations were prepared from $0.3 \mathrm{ml}$ aliquots. ${ }^{1}$ Paired CSF and serum specimens were sent to reference laboratories for virological serology: measles, cytomegalovirus, Epstein-Barr virus, mumps, rubella, herpes simplex (HSV) 1 and 2 , hepatitis B virus, human $T$ cell leukaemia virus (HTLV) 1 and 2, human immunodeficiency virus (HIV).

Specialized CSF investigations included oligoclonal immunoglobulin banding, enzyme-linked immunosorbent assay (ELISA) and reverse Western blotting (immunoblotting) were conducted using standard methods ${ }^{2}$ against a panel of antigens including measles, HSV 1 and 2, varicellazoster virus (VZV), HTLV 1, toxoplasma and sarcoid antigens.

Microbiological investigations included CSF mycobacterial antigen assay (Department of Microbiology, Hospital for Sick Children, Great Ormond Street, London), myobacterial culture, routine culture and serology for Legionella, Listeria, Coxiella, Rickettsia, and parasitological serology included assays for toxoplasma, toxocara, Borrelia burgdorferi and syphilis. 
Results

Haematological investigations revealed a haemoglobin of $12 \mathrm{~g} / \mathrm{dl}$, leukocytes $3.6 \times 10^{9} / 1$ (neutrophils $\left.1.6 \times 10^{9} / 1\right)$ and platelets $297 \times 10^{12} / 1$, ESR $124 \mathrm{~mm} /$ hour with a blood film containing some hairy cells and showing the effects of splenectomy. The presence of hairy cells was confirmed by staining for tartrate-resistant acid phosphatase (TRAP). The leukocyte differential was macrophages $15 \%$, polymorphonuclear neutrophils $44 \%$, lymphocytes $36 \%$, plasma cells $3 \%$ and hairy cells $2 \%$. Serum biochemistry was normal. All virological, parasitological and immunological investigations were negative apart from toxoplasma serology in blood and CSF (serum IgM $1 / 320$, CSF titre $1 / 2,560$ ) and a high CSF measles antibody titre $(1 / 512)$ (serum $1 / 32$, normal).

CSF cytology showed an intense lymphocytic reactive picture $(>100 \times 10$ lymphocytes $/ 1 ; 58 \%$ B-cells, 34\% T-cells), with large numbers of plasma cells $(6 \%)$ and a few hairy cells $(1 \%)$. CSF protein was $1.39 \mathrm{~g} / 1$ and glucose $2.9 \mathrm{mmol} / 1$ (plasma $3.7 \mathrm{mmol} / \mathrm{l}$ ). CSF biochemistry revealed an acute phase reaction (orosomucoid:transferrin ratio 0.28 , reference limit $<0.20$ ), damage to the blood-brain barrier (group components:tau ratio 1.83 , reference limit $<1.00$ ), and a number of oligoclonal bands. More bands were seen in the CSF than in the serum showing intrathecal immunoglobin synthesis. However, some bands were present in both serum and CSF indicating the presence of serum leakage. ELISA assays were positive for measles, HSV1 and VZV antigens. Immunoblotting of the CSF against specific antigens showed oligoclonal bands reactive only against toxoplasma. A CSF specimen from day 7 showed resolution of the B-cell lymphocytosis and immunocytochemical staining showed $90 \%$ of the remaining cells positive for CD3, CD25 but negative for CD19, CD45, Ig, HLA-DR. This was consistent with a primarily $\mathrm{T}$-cell reactive picture. The low number of hairy cells per field relative to lymphocytes made it difficult to identify them definitively as CD19, CD25, HLA-DR positive, ${ }^{3}$ but they were revealed by the use of TRAP staining. Later CSF specimens (day 14) showed a resolution of the lymphocytosis leaving solely hairy cells in the CSF on the basis of morphology and being TRAP positive, which disappeared in subsequent specimens (day 30 , day 60 ) leaving only the occasional lymphocyte $\left(<3 \times 10^{6} / \mathrm{ml}\right.$ - normal).

\section{References}

1. Norman P.M. CSF cytology. In: Coleman, D.B. \& Chapman, P.S. (eds) Clinical Cytotechnology. Butterworths, London, 1989, pp. 293-302.

2. Moyle, S., Keir, G. \& Thompson, E.J. Viral immunoblotting: a sensitive method for detecting viral-specific oligoclonal bands in unconcentrated cerebrospinal fluid. Biosci Rep 1984, 4: $505-510$.
The final diagnosis was encephalomyelitis secondary to toxoplasma infection with reactivation of measles, HSV 1 and VZV viruses.

\section{Discussion}

Hairy cell leukaemia was originally described by Bouroncle in 1958 and she has since reviewed 116 cases for unusual complications including central nervous system involvement. ${ }^{4}$ The four case reports in the literature $\mathrm{e}^{4-7}$ are suspected of being secondary to undiagnosed infections or cyptococcal meningitis ${ }^{4}$ but none of these cases documented the state of the blood-brain barrier. In this case hairy cells were seen in the CSF secondary to blood-brain barrier disruption by meningitis and they disappeared as the barrier reformed.

Toxoplasmosis is a rare infection in HCL and can be caused by reactivation of dormant cysts as well as acute infection ${ }^{8}$ whilst viral reactivation is frequently seen in the immunocompromised. The defect in cell-mediated immunity in HCL predisposes patients to opportunistic infections ${ }^{8}$ and there is also an association of vasculitis with $\mathrm{HCL}$ (possibly related to chronic infections). ${ }^{9,10}$ Both toxoplasmosis and its associated inflammatory response and HCL-related vasculitis were probably responsible for the meningitis seen in this case.

Hairy cells were seen in the CSF in this patient it the context of a florid inflammatory picture and its resolution. However, if a patient had had a single CSF specimen taken after a mild infection or following an exacerbation of cerebral vasculitis, the presence of hairy cells in the CSF may have led to inappropriate intrathecal chemotherapy being given.

We suggest that CSF-HCL is a secondary selflimiting phenomenon following infection or cerebral vasculitis and that chemotherapy ought not to be prescribed unless the diagnosis of malignant infiltration in the absence of inflammatory leakage is certain.

\section{Acknowledgements}

We would like to thank Dr R. Kocen (National Hospital for Neurology and Neurosurgery) and Sir John Batten (King Edward VII Hospital for Officers) for permission to use their clinical data and Professor T.A. Lister (St Bartholomew's Hospital) for providing later CSF specimens.

3. Hassan, I.B., Hagberg, H. \& Sundstrom, C. Immunophenotype of hairy cell leukaemia. Eur J Haematol 1990, 45: 172-176.

4. Bouroncle, B.A. Unusual presentations and complications of hairy cell leukemia. Leukemia 1987, 1: 288-293. 
5. Wolfe, D.W., Scopelliti, J.A. \& Boselli, B.D. Leukemic meningitis in a patient with hairy cell leukaemia (case report). Cancer 1984, 54: 1085-1087.

6. Plendreith, I.H. Hairy cell leukemia. Can Med Assoc J 1978, 102: $1056-1060$.

7. Cotelingam, J.D., Knop, R.H., Garvin, D.F., Mercado, T.C. \& Schumacher, H.R. Hairy cell leukemia. N Engl J Med 1983, 308: 47.
8. Knecht, H., Rhyner, K. \& Streuli, R.A. Toxoplasmosis in hairy cell leukemia. Br J Haematol 1986, 62: 65-73.

9. Westbrook, C.A. \& Golde, D.W. Autoimmune disease in hairy cell leukemia: clinical syndromes and treatment. $\mathrm{Br} J$ Haematol 1985, 61: 349-356.

10. Farcet, J.-P., Wechsler, J., Wirquin, V., Divine, M. \& Reyes, F. Vasculitis in hairy cell leukemia. Arch Intern Med 1987, 147: $660-664$.

\title{
Haemolytic-uraemic syndrome with thrombotic microangiopathy of the retina following cytomegalovirus infection: postmortem findings
}

\author{
Blanca Catón, Ramón Díaz de Otazu, Mikel Aldamiz-Echebarria and Amparo \\ Viguri
}

Departments of Pathology and Internal Medicine, Hospital Txagorritxu, 01009 Vitoria, Spain

\begin{abstract}
Summary: Haemolytic-uraemic syndrome is characterized by thrombotic microangiopathy of the glomeruli and smaller arterial vessels of the kidney. Extrarenal thrombotic microangiopathy occurs, but ocular involvement is rarely demonstrated microscopically. We describe a 33 year old woman with a 3 week febrile episode and seropositivity for cytomegalovirus infection who developed acute renal failure, blindness and severe encephalopathy which was the cause of death. Thrombotic microangiopathy of retinal vessels may be more common than is expected from the literature. The exclusion of ocular structures in postmortem examinations explains the lack of anatomoclinical correlation.
\end{abstract}

\section{Introduction}

The haemolytic-uraemic syndrome is a clinical entity, defined by microangiopathic haemolytic anaemia, thrombocytopenia and acute renal failure, whose underlying histopathological feature, thrombotic microangiopathy, is also found in thrombotic thrombocytopenic purpura. ${ }^{1-3}$ Haemolytic-uraemic syndrome and thrombotic thrombocytopenic purpura are considered by some authors ${ }^{1}$ as a different clinical expression of the same disease. Thrombotic microangiopathy always involves the glomeruli and smaller arterial vessels of the kidney, but sometimes spares the extrarenal vascular beds. Ocular structures affected by the thrombotic microangiopathy of haemolyticuraemic syndrome have been occasionally described..$^{4-8}$ The present case appears to be the first for haemolytic-uraemic syndrome following cyto-

Correspondence: Ramón Díaz de Otazu, M.D., Departamento de Anatomía Patológica, Hospital Txagorritxu, 01009 Vitoria, Spain.

Accepted: 11 January 1993 megalovirus infection with documented retinal histology at autopsy.

\section{Case report}

A 33 year old women presented with a 3 week history of fever. The patient's medical history was unremarkable. On the following days after admission to the hospital, the patient developed periorbital oedema, hypoproteinaemia with no evidence of proteinuria and decreased visual acuity which was attributed to an acute exudative chorioretinitis with peripapillary retinal oedema. Blood pressure was normal. Treatment with corticosteroids was unsuccessful and acute renal failure developed. The serum creatinine level was $707 \mu \mathrm{mol} / 1$ (normal $<123 \mu \mathrm{mol} / \mathrm{l})$. Laboratory tests disclosed microangiopathic haemolytic anaemia (haemoglobin $6.5 \mathrm{~g} / \mathrm{dl}$ ) reticulocytes $5.8 \%$, platelet count $106 \times 10^{9} / 1$, schistocytes ++++ , haptoglobin $<0.25 \mu \mathrm{mol} / 1$ (normal $0.27-1.21 \mu \mathrm{mol} / \mathrm{l}$ ) and 